\title{
PROTAGONISMO DA ENFERMAGEM BRASILEIRA NO COMBATE À COVID-19
}

\author{
Manoel Carlos Neri da Silva ${ }^{1}$ \\ Carlos Leonardo Figueiredo Cunha ${ }^{1}$ \\ Francisco Rosemiro Guimarães Ximenes Neto ${ }^{1}$ \\ José Luis Guedes dos Santos ${ }^{1}$ \\ Luciano Garcia Lourenção ${ }^{1}$ \\ Neyson Pinheiro Freire ${ }^{1}$ \\ Isabel Cristina Kowal Olm Cunha ${ }^{1}$
}

\author{
https://orcid.org/0000-0002-3923-7473 \\ https://orcid.org/0000-0002-1891-4201 \\ https://orcid.org/0000-0002-7905-9990 \\ https://orcid.org/0000-0003-3186-8286 \\ https://orcid.org/0000-0002-1240-4702 \\ https://orcid.org/0000-0002-9038-9974 \\ https://orcid.org/0000-0001-6374-5665
}

Em 2020, comemora-se o Bicentenário de Florence Nightingale, enfermeira responsável pelo desenvolvimento das bases técnico-científicas da Enfermagem Moderna. Para celebrar esta data, a Organização Mundial de Saúde (OMS) e o Conselho Internacional de Enfermeiros (International Council of Nurses - ICN) lançaram, em 2018, a Campanha "Nursing Now"(1-2), com o objetivo de fortalecer a educação e o desenvolvimento dos profissionais da área de Enfermagem, com foco na liderança, na melhoria das condições de trabalho e no compartilhamento de práticas exitosas e inovadoras, baseadas em evidências científicas em âmbito nacional e regional,

No Brasil, a iniciativa é liderada pelo Conselho Federal de Enfermagem (Cofen) e pelo Centro Colaborador da Organização Pan-Americana da Saúde (OPAS/OMS) para o Desenvolvimento da Pesquisa em Enfermagem, vinculado à Escola de Enfermagem da Universidade de São Paulo (USP), de Ribeirão Preto(2).

Além da Campanha Nursing Now, a OMS durante a Assembleia Mundial da Saúde de 2019, elegeu 2020, como o "Ano Internacional dos Profissionais de Enfermagem e Obstetrícia", buscando alertar para o mundo a necessidade de um maior contingente desses profissionais, além da melhoria de suas condições de trabalho, educação e desenvolvimento profissional.

Ao início das comemorações pelo "Ano da Enfermagem", em 12 de janeiro de 2020, a OMS divulgou notícias sobre um surto com um novo coronavírus, originado em Wuhan, província de Hubei, China. A doença (COVID-19) se propagou para diversos países, sendo declarada pandemia pela OMS no mês de março ${ }^{(3-4)}$. O primeiro caso confirmado em território brasileiro e na América Latina ocorreu em 26 de fevereiro de 2020. Desde então os profissionais da Enfermagem têm se destacado por atuarem na linha de frente à prevenção e ao combate da doença, buscando mitigação da pandemia.

Diante da ausência de uma vacina e medicamentos antivirais específicos, os ensinamentos de Florence Nightingale nunca estiveram tão atuais. Medidas como a lavagem das mãos, a limpeza dos hospitais e dos ambientes domésticos, e a implementação de boletins epidemiológicos como medidas de acompanhamento da doença e da curva epidêmica(5), tornaram-se imprescindiveis para o combate desta doença.

Em pleno Ano Internacional de comemoração da Enfermagem, esta pandemia jogou luzes sobre a importância desses profissionais, no âmbito da assistência, da gestão e do ensino em saúde, constituindo-se como espinhas dorsais de sustentabilidade dos serviços de saúde. De forma mais frequente, a imprensa passou a destacar o trabalho da Enfermagem, seu protagonismo junto ao Sistema Único de Saúde (SUS), além de desvelar as condições de trabalho, o adoecimento e a morte daqueles que enfrentam com honradez a pandemia e as consequências destas em suas vidas profissionais e pessoais.

Segundo o relatório "State of the World's Nursing 2020"(6), da OMS em parceria com o ICN, no mundo existem cerca de 28 milhões de profissionais de Enfermagem. No Brasil, dados do Cofen mostram que há mais de dois milhões de profissionais presentes na totalidade dos municípios brasileiros, em todos os níveis de atenção à saúde ${ }^{(7)}$. Esses dados indicam que nenhuma agenda global pode ser concretizada sem esforços articulados e sustentáveis, para maximizar a contribuição da força de trabalho da Enfermagem e seu papel em equipes de saúde multiprofissionais.

${ }^{1}$ Membros do Conselho Diretor da Revista Enfermagem em Foco. Conselho Federal de Enfermagem, Brasília, DF.

8 | Enferm. Foco 2020; 11 (1) Especial: 8-9 
Todavia, não se pode deixar de pontuar as situações de vulnerabilidades profissionais da Enfermagem no país, no que tange às condições e carga horária de trabalho, inexistência de um piso salarial emprego, plano de carreira, dentre outros. Nesse sentido, aos profissionais de Enfermagem precisam ser asseguradas políticas e medidas governamentais que contribuam para a prática segura e efetiva do cuidado, tendo em vista que, até o dia 17 de junho, mais de 200 profissionais de enfermagem morreram vitimas da COVID-19 e mais de 19 mil se infectaram $^{(8)}$ devido à falta de condições dignas de trabatho, como o acesso contínuo e de qualidade aos Equipamentos de Proteção Individual (EPI), o dimensionamento adequado das equipes e a proteção dos trabalhadores que integram os grupos de risco.

Além de reforçar o papel da Enfermagem, a pandemia da COVID-19 no país está reafirmando a importância do sistema público de saúde, dos centros de pesquisas, das universidades e do seu tripé educacional (Ensino, Pesquisa e Extensão), para construção de uma sociedade mais justa, igualitária e saudável.
Face ao exposto, a Enfermagem coloca-se, então, como um campo fértil de pesquisas e intervenções. Este número especial da Revista Enfermagem em Foco contém 62 artigos, nos formatos de artigos originais, reflexão, opinião, revisão narrativa e integrativa, inovação e relatos de experiências, versando sobre a atuação de Enfermagem em diferentes perspectivas: epistemológica, política, organizacional, de formação e ainda dos saberes e práticas em saúde. Ao total, foram recebidos 172 manuscritos para a chamada especial, vindos das cinco regiões do Brasil.

Os manuscritos publicados refletem a criatividade $e$ inovação dos profissionais de enfermagem, possibilitando aos leitores o aprendizado da prática e ciência da Enfermagem, com o intuito de apoiar e aprimorar o cuidado em saúde diante dos desafios trazidos pela pandemia da COVID-19. E a Revista Enfermagem em Foco cumpre sua missão de contribuir para o fortalecimento da Enfermagem a partir da divulgação da produção do conhecimento, em consonância com os objetivos do Sistema Cofen/Conselhos Regionais de Enfermagem.

Avante Enfermagem Brasileira!

Descritores: Enfermagem; Pandemia; Infecções por Coronavírus.

\section{PROTAGONISMO DE ENFERMERÍA BRASILEÑA EN LA LUCHA CONTRA COVID-19}

Descriptores: Enfermería; Pandemia; Infecciones por Coronavirus.

\section{PROTAGONISM OF BRAZILIAN NURSING IN THE FIGHT AGAINST COVID-19}

Descriptors: Nursing; Pandemic; Coronavirus Infections.

REFERÊNCIAS

1. Cassiani SHB, Lira Neto JCG. Nursing Perspectives and the "Nursing Now" Campaign. Rev Bras Enferm [Internet]. 2018 [cited 2020 Jun 13]: 71(5):23512. Available from: http://dx.doi.org/10.1590/0034-7167.2018710501.

2. Mendes IAC. Agora, sim!!! Lançamento da Campanha Nursing Now Brasil. Enferm Foco [Internet] 2019 [citado 2020 Jun 17]; 10(2):1-3. Available from: <http://revista.cofen.gov.br/index.php/enfermagem/article/view/2331>. Acesso em: 17 jun. 2020. doi:https://doi.org/10.21675/ 2357-707X.2019.v10.n2.2331.

3. Guan W, Ni Z, Hu Y, Liang W, Ou C, He J et al. Clinical Characteristics of Coronavirus Disease 2019 in China. N Engl J Med [internet]. 2020 [cited 2020 Jun 13]: 382:1708-1720. Available from: https://doi.org/10.1056/NEJMoa2002032.

4. World Health Organization (WHO). Emergencies preparedness, response: Novel Coronavirus - China - Disease outbreak news: Update, 12 January 2020. [Internet]. 2020 [cited 2020 Jun 17]; Available from: https://www.who. int/csr/don/12-january-2020-novel-coronavirus-china/en/.
5. McEnroe N. Celebrantig Florence Nightingale'sbicentenary. The Lancet [Internet]. 2020. [cited 2020 Jun 15]; 395(10245):1475-78. Available from: https://doi.org/10.1016/S0140-6736(20)30992-2.

6. World Health Organization (WHO). State of the world's nursing 2020 [Internet]. Genebra; 2020 [cited 2020 Jun 14]. Available from: https://apps.who. int/iris/bitstream/handle/10665/331673/9789240003293-eng.pdf.

7. Silva MCN, Machado MH. Sistema de Saúde e Trabalho: desafios para a Enfermagem no Brasil. Ciênc. saúde coletiva [Internet]. 2020 Jan [citado 2020 Jun 17]; 25(1):7-13. Available from: http://www.scielo.br/scielo.php?script=sci_arttextEpid=S1413-81232020000100007\&lng=pt. Epub 20-Dez2019. https://doi.org/10.1590/1413-81232020251.27572019.

8. Conselho Federal de Enfermagem (Cofen). Observatório de Enfermagem. Profissionais infectados com COVID-19 informado pelos enfermeiros responsáveis técnicos/coordenadores. [Internet] 2020 [Cited in 2020 Jun 17] Available from: http://observatoriodaenfermagem.cofen.gov.br/. 